\title{
MUSEERNA PÅ DEN DIGITALA SCENEN
}

Per-Uno Agren

IT i kulturens tjänst är titeln på en svensk statlig utredning (SOU 1997:14) som föreslår uppbyggnaden av ett digitalt Kulturnät Sverige. Under utredningsarbetet arrangerades konferenser, där tänkbara intressenter fick ge synpunkter på utredarnas idéer. Följande kommentarer gjordes vid en konferens som kretsade kring begreppet digitala mötesplatser. Som en sådan presenterades bl.a. Den digitala salongen, med deltagare från flera kulturområden som fungerat sedan 1993. Den hade inspirerats av den konkreta erfarenheten av samvaron i ett musikkafé.

Ett museum kan naturligtvis vara en lika konkret mötesplats - särskilt interessanta förefaller mig museets egenskaper i just det avseendet: hur en historisk och visuell erfarenhet och information medieras - särskilt $i$ utställningsform - och hur den uppfattas av mötesplatsens besökare. Alltså, om uttrycket tillåts, själva användargränssnittet.

Skulle denna konkreta mötesplats kunna transformeras till en digital salong?

1.

Den outtröttlige museiälskaren (och museikritikern) Kenneth Hudson skrev nyligen:

Museerna måste välja en framtid som siktar på en bättre besökarkvalitet. Ett felaktigt val innebär en utställningspolitik som bara syftar till och antagligen ger en större mängd besökare utan att man bekymrar sig om deras kvalitet. En bättre besökarkvalitet förutsätter att museet erbjuder en bättre kvalitet på besöket... En god besökare är den som är mentalt nyfiken och som kommer till museet för att vidga sin erfarenhet, öka sitt vetande och upptäcka nya glädjeämnen. En medioker besökare är i museet bara för att fördri- va tiden och lämnar det i samma mediokra tillstånd som han kom. Ett museums uppgift är att locka och tillfredsställa de goda, seriösa, besökarna. Dessa är sorgligt nog bara en minoritet, vilket bara är ett annat sätt att medge att goda museer antagligen inte lockar stora besökarmassor. Museer bör när det kommer till kritan, väsentligen finnas till för tänkande människor och såna finns dessvärre bara i begränsat antal, även om de finns i alla samhällsgrupper. (Nordisk Museologi 1996/1, s 125)

Kenneth Hudson uttrycker sig öppenhjärtigt brutalt - men hans kategoriindelning möter inte sällan i mer beslöjade ordalag när museernas publik diskuteras. $\AA$ ena 
14 sidan finns de aktiva kunskapssökarna, å andra sidan de tidsfördrivande, underhållningssökande flanörerna, skyltfönstertittarna eller vad man vill kalla dem. De brukar tydligt avteckna sig i besöksstatistiken under regniga somrar.

Kunskapssökarna, forskarna på akademisk nivå och de glada amatörerna, är den kategori som haft största nyttan av den utveckling som ägt rum under senare år när museernas datasamlingar gjorts alltmer tillgängliga. Så i de allt talrikare $s \mathrm{k}$ faktarummen och i de vägar in i museernas minne som datoriseringen möjliggör, särskilt när den till föremålssamlingarna knutna informationen på ett alltmer sofistikerat sätt kopplas till uppgifter såväl i museibiblioteken, skrift- och bildarkiven som i externa kunskapskällor. IT-utvecklingen på det området är glädjande både för de anställda och för de forskande besökarna. Båda grupperna är klart motiverade att snabbt lära sig hantera redskapen för att kunna utnyttja denna expanderande minnesbank.

Kunskapssökarna sönderfaller i ett par viktiga grupper - den ena hör hemma i hembygdsrörelsen, drivs av lokalhistoriskt och släktforskningsintresse; den andra har särskilt intresse för det materiella kulturarvets visuella egenskaper - för hur den yttre miljön förändrats över tid, hur odlingslandskap, bebyggelse sett ut, hur industriell verksamhet, kommunikationer, handel påverkat landskapsbilder, hur den materiella tingkulturens formtraditioner tett sig; hur människor sett ut i sitt privata och sociala liv. För denna nyfikenhet på det synliga, erbjuder den växande åtkomligheten $\mathrm{i}$ museernas bildsamlingar otroligt mycket som stimulans i miljöengagemang och formskapande.
Lägg till dessa båda grupper, en tredje, bestående av de ungdomar som i studieuppgifter av olika slag åläggs att bekanta sig med det historiska källmaterialet i museernas minnesförråd.

För dem alla är det ofta tillräckligt att erbjudas tillträde till museernas databaser - och det är självklart att man i varje museum måste utarbeta planer för att tillgodose också de människor som inte har museet fysiskt inom räckhåll med möjligheter att utnyttja detta minne - det är ju också deras kulturarv som förvaltas! Man måste självklart sträva efter att så långt som möjligt göra det tillgängligt i lämpliga nätverk. Det är särskilt i detta sammanhang det distribuerade museet är en viktig möjlighet.

2.

Men de tidsfördrivande flanörerna och icke-besökarna - ska de med sitt ointresse lämnas åt sitt öde? Kenneth Hudsons desillusionerade beskrivning av dem (som har motsvarighet i många publikstudier) kan inte lämna en svensk folkrörelsepräglad bildningsentusiast någon ro. Finns det något sätt att väcka nyfikenhet och kunskapstörst som bryter den, inte helt ovanliga, blaserade besökarens likgiltighet inför historiens vikt och mening? Jag tror att vi ständigt måste utveckla och förnya museernas berättande. Alla vet vad det betyder att möta goda berättare - de som med sin inlevelse, sina ord, tonfall och förmåga till konkretisering plötsligt gör förflutet liv närvarande och mänskligt angeläget. Detsamma gäller det visuella berättandet i det som är museernas essentiella informationsteknik - utställningarna. 
3.

Museerna handlar om tid och rum. Men museernas visuella språk är som bekant rumsligt. Tanken var ursprungligen att man kunde sätta historien i rörelse genom att vandra genom utställningsrummen. I besökarens medvetande skulle tidsdimensionen automatiskt återskapas genom jämförelsen mellan de olika formspråk som mötte blicken. Samtidigt skulle i stillheten omkring tingen uppstå en annan känsla av tidlösheten i människans liv och strävan. Men det vore fel att förneka att för många i stället intrycket av dammigt stillastående dominerat, att museiledan infunnit sig.

\section{4.}

Det är lätt att glömma att museet är ett sceniskt medium. Museet tvingar sina användare att komma dit för att se - som till en teater eller konsertlokal. Också i dem kan man uppleva stillastående och gäspande tråkighet: det är ju samma texter som framförs, samma stycken som spelas. Men det är framförandet, iscensättningen som räknas - liksom i museernas utställningar av det förflutnas ting, sedda men dessvärre samtidigt osynliggjorda, förbrukade i rutinmässiga schablonhistorier. Det är den oväntade ljussättningen, tolkningens personliga tonfall, den överraskande skälvning som det obegripliga, gåtfulla eller föremålets aura ger, som kan väcka gruppresornas och skolklassernas tvångskommenderade slötittare.

I alla medier gäller att arbeta med de mediespecifika uttrycksformerna - museiutställningens särart ligger primärt i tingens och bildernas faktiska närvaro och visualitet. Men dess berättande har en rar andra medier - ljud, ljus, projektioner. Det talas ofta om den scenografiska trenden i dessa utställningars mediapaket. Iscensättningen syftar ofta till att besvärja en tidsdimensionens tydligare närvaro därför utnyttjas också den rörliga bilden i allt större utsträckning. Samtidigt blir det möjligt att ge plats åt och inarbeta i utställningsspråket resultaten av den foto-, film-, och videodokumenterande verksamhet, liksom den muntliga historia som registrerats på ljudband (allt detta som från 1960- och 70-talen blivit ett självklart komplement till föremålssamlandet) och därmed fördjupa och förstärka berättandet. Detta mångmediala utställningsspråk, som kräver alltmer professionellt kunnande och regikonst av utställningsskaparen, borde rimligtvis kunna stimulera nyfikenheten på det gemensamma samhällsminnet, en nyfikenhet som kunde ytterligare tillgodoses med hjälp av en dataterminal intill utställningen. Utom att öppna vägarna in i en fördjupande digitaliserad information skulle själva utställningsprojektets bakgrund och framväxt kunna göras tillgängliga för den källkritiskt intresserade.

I en utställning våren 1996 i Amsterdams stadsmuseum om kurdernas situation - både i Turkiet och som invandrare i Holland - kunde man se datortekniken tillämpad för att möjliggöra ett digitalt regisserat möte. Invandrare gav inför en kamera synpunkter på utställningen och berättade om sina egna erfarenheter. För efterföljande besökare var det möjligt att på bildskärmar hämta fram och ta del av synpunkterna - och att eventuellt själva kommentera dem inför samma kamera. 
Bland museernas brukare är det särskilt en grupp som anses viktig - de unga människorna. De är under sin uppväxt upptagna av att lära sig använda den omgivande miljön, lära sig vad den betyder och hur den fungerar; vilka möjligheter den erbjuder. De fäster den vid sig med upplevelser och känslor, tar den till sig som existerande nu. Har den någonsin sett annorlunda ut, varit beskaffad på något annat sätt? Den historiska dimensionen är osynlig, först levandet och minnandet gör att tiden blir fattbar i människans medvetande.

Men televisionens medierade världsbild har ofantligt vidgat omvärldens utsträckning och ytliga påtaglighet, för tittaren som snabbt svappar mellan kanalerna. Kommer därtill uppkopplingen till Internet och de meningslösa struntsamtalen i häftiga transnationella möten. Var finns omvärldens gränser, hur ska verkligheten definieras? Allt finns på ett illusoriskt sätt inom räckhåll. Virtuost, rastlöst överstimulerat rör sig medvetandet genom det virtuella rummet, rumsupplevelsen är gränslös - man kan förmoda att den postmoderna upptagenheten av ytor och utseenden har med den sortens visuella omättlighet att göra.

Mot slutet av 1960-talet knöts stora förhoppningar till undervisningsteknologi, programmerad undervisning, inlärningslaboratorier. Den lärarlösa skolan hägrade för många. Men meningsfulla kunskapsprocesser visade sig ganska snart inte fungera utan levande och närvarande lärare. $\mathrm{Nu}$ förefaller det som om datorerna med sina enorma möjligheter omärkligt blivit en ny styrande undervisningsteknologi. Bildskärmar frestar med sin diskreta närvaro i alla rum till ständiga utflykter, glo-

bala resor i det virtuella kunskaps- och upplevelselandskapet, utflykter som lätt blir undanflykter.

I en PM om museernas IT-projekt till statens kulturråd (KMU: 94/95:12) skriver Katarina Ek-Nilsson att tanken att med hjälp av IT i museerna locka fler ungdomar, förefaller vara något passé. I accelererande takt blir för den yngre generationen alltmer av IT-världen ett naturligt och trivialt inslag $\mathrm{i}$ vardagen. Datorer och multimedia utgör i sig snart ingen särskild attraktion för barn och ungdomar; allt fler får $\mathrm{i}$ hem och skola tillgång till Internet, i stort sett alla har egna TV-spel. Kanske blir det i stället så, att det som museerna ensamma är bra på: att berätta historia med hjälp av föremål, originaldokument och fysisk gestaltning blir det verkligt fantasieggande och lockande?

Man kan också uttrycka det så att

Museerna vill återbörda människorna till verkligheten, konkretisera sprăkvärldens och bildvärldens abstraktioner. Utställningarna blir modeller av världen, där byggstenarna är verkligheten själv.

(Inlägg vid IT-konferens i Malmö 1/2 1996)

Att tillföra - särskilt för ungdomen - den förlorade historiska dimensionen i den synliga platta rumsvärlden!

Museiverksamhet handlar om människor, att erbjuda mänsklig kontakt som förenar förr, nu och framtiden; att det vi kan erbjuda ligger just i mötesplatser och i det sinnliga.

(Sten Rentzhog i Nordisk Museologi 1996/1, s 29) 
6.

När man ställs inför nya medier som informationsbärare, aktualiseras genast en rad grundläggande frågor beträffande informationsförsörjningen inom ens eget speciella område.

Den optimism som finns hos många ITideologer, som tänker sig att

de gamla maktstrukturerna ska upplösas sedan den digitala revolutionen gått segrande fram över jorden och att bara informationen ska vara fri, ska det nog fixa sig med arbetslösheten, fattigdomen och krigen (Kjell Jonsson i Västerbottens-Kuriren 15/51996)

- den optimismen lät lika övertygande i 1800-talets visioner inför folkskolan och den begynnande masspridningen av böcker och tidningar till 'folket' eller på 1920-talet i drömmarna om radions kulturrevolutionerande möjligheter eller under den $s \mathrm{k}$ efterkrigstiden i de förhoppningar som knöts till televisionen. Idéhistorikern vet, försiktigt uttryckt, att tekniken ensam inte löser våra problem.

Vi kan också lätt se att det mediespecifika i museernas kommunikation med sin brukare är artskilt från hela raden av de förmedlingsformer jag nämnde. Samtidigt att alla sceniska uttrycksformer utvecklat framgångsrika symbioser med nya tekniker genom att skapa nya övertygande formspråk - teatern med radion gav de nya hörspelen; litteraturen och teatern med filmen, liksom med televisionen gav TV-teatern och TV-filmen som onekligen blivit egna genrer.

Vi som en gång försökte driva på användningen av film och video i museerna, som drömde om de videodistribuerade utställningarna $\mathrm{i}$ ett museernas eget nät- verk; som hoppades på bildspelen och hologrammen - de delade ju visualiteten som grundläggande element med museerna! - vi har sett, att teknikerna för att bli bra och utvecklas i museimiljön, kräver installationer och en professionalism som inte visat sig lätt eller ens möjlig att infoga i museernas strukturer.

Datorn har på samma självklara sätt som skrivmaskin, stencilapparat och kopiator kunnat tas emot som skrivverktyg i textproduktion och som datalagringsmöjlighet med oöverträffat snabba och effektiva sökmöjligheter. Men vägen är sannolikt lång till det distribuerade museet i den meningen, att de visuellt gestaltade historiebilder och verklighetstolkningar som museernas utställningar presenterar, på ett mediespecifikt sätt ska kunna göras tillgängliga på CD-ROM och i distributiva nätverk för att nå dem som har museerna utom dagligt räckhåll. Den virtuella museiutställningen är en självmotsägelse. $\mathrm{Vi}$ anar visserligen möjligheterna - att kunna närma sig föremål och bilder i serier av detaljförstoringar, att interaktivt kunna välja bildvinklar och bildutsnitt, att kunna knyta objekten till andra ting och bilder, texter och röster, filmsekvenser. Men detta kräver en egen gestaltning, en egen symbios mellan utställningsmediet och de digitala mediernas bildskärm kort sagt en ny professionalism. Det är först då överflyttningen av museiutställningarna till en digital salong skulle med någon sorts mening kunna genomföras.

Museerna bedriver sin verksamhet mellan lärande och underhållning. I den mediala konkurrensen om uppmärksamhet frestar hybriderna 'infotainment' och 'edutainment' som lockande begrepp och möjligheter. Det är nödvändigt för oss att 
PER-UNO $\AA$ GREN

18 kunna forma dem på ett så inspirerande och förtroendeingivande sätt att det ger museerna, den historiska erfarenhetens företrädare, en lika självklar och omistlig plats som biblioteken $\mathrm{i}$ vår medborgerliga offentlighet.

\section{SUMMARY}

Museums on the digital stage

In Sweden a recent State Report has proposed the establishment of a digital Cultural network ('Kulturnät Sverige') on the Internet. In the preparation of the Report several hearings were arranged in 1996, among them

one about the usefulness of such a network for museums. This text was written for that occasion.

An attempt is made to define the unique qualities of the museum exhibition in comparison with other media of communication in the cultural field. It has been argued that museums have an obligation to use digital techniques to put their collections at the disposal of a global Internet public who could at any time enter the museum to take a look at its exhibitions and to study all its stored objects. However this availability has serious limitations; it lacks many of the basic aspects of the museum proper - the spatial experience of its galleries, the three-dimensional physical qualities - form, texture, colour - of its objects. The museum exhibition - like all performing arts - may seem to be a demanding medium, because it asks from us the tribute of a personal visit to yield in full measure its capacity to excite our senses and trigger our imaginations. Perhaps, in the future, successful hybrid forms of the 'real' exhibition and mediated images of it may develop, in the same way as literature, music and theatre have successfully teamed up with radio and television in specific new genres.
Texten är en bearbetat version av «Museerna som distribuerade kunskapscentra». I «Kultur på nätet den digitala mötesplatsen och museernas nya arenor. Workshop 2 Kultur på nätet». Kulturnät Sverige Rosenbad 24 maj 1996.

\section{Internetadiesse}

Kulturnät Sverige: www.kulturnat.iva.se

Per-Uno Agren är ansvarshavande redaktör för Nordisk Museologi.

Adr: Mariehemsuägeb 11G, S-906 54 Umeå

Fax +46-90-139852

e-mail: Per-Uno.Agren@museologi.umu.se 